\title{
Small Scale Correlation between the Electrical and the Hydraulic Conductivity
}

\author{
Flemming Effersø and Kurt I. Sørensen \\ Geophysical Laboratory, Department of Earth Sciences, Aarhus University
}

\section{Introduction}

There has been an ongoing discussion about the relationship between the hydraulic and the electrical conductivity. In order to test this relationship on a small scale a new method for in situ determination of the hydraulic conductivity has been developed at the Department of Earth Sciences. In a series of field tests in a sandy alluvium, estimates of the hydraulic conductivity were obtained in three closely spaced borings together with gamma and electrical logs. The results indicate that there is no evident relationship between the electrical conductivity and the hydraulic conductivity on a small scale.

\section{The method}

The measuring tools are integrated in a hollow stem auger (see Figure 1), and measurements are performed at different levels of the formation.

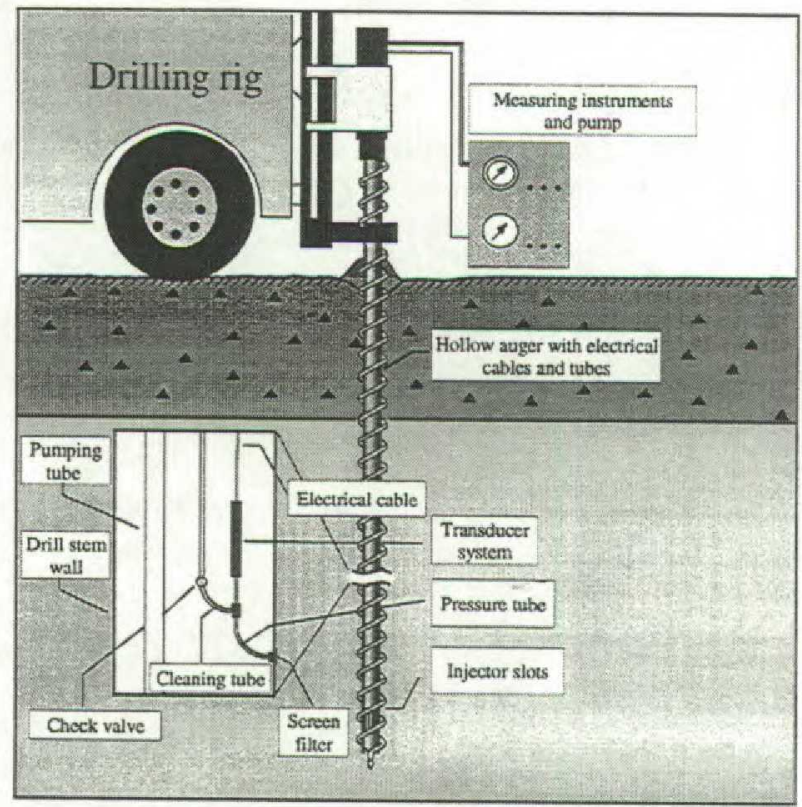

Figure 1: Principle of the injection method.

Through slots next to the cutting head, a constant water flow is injected into the formation. The rise in hydraulic head outside the drilling stem is measured by an array of transducers located $0.46,0.88$, 1.24 , and $1.78 \mathrm{~m}$ above the injector slots. The injector slots have a height of $0.20 \mathrm{~m}$ and they are equally spaced around the drilling stem. The transducer systems, which are mounted inside the drilling stem, measure the rise in hydraulic head in the formation. The pressure is conveyed to the transducer system through a pressure tube that enters a hole in the drilling stem. A screen filter is placed in front of this hole to prevent obstruction of the tube. Before measuring the screen is cleaned 
by water pumped through a cleaning tube connected to the pressure tube. The water injected into the formation is pumped down from the surface.

All data acquisition takes place in the transducer systems, and data is transmitted in digital form to a PC on the ground. The rise in hydraulic head and the injected water flow are sampled with a frequency of 63 milliseconds, and a detailed resolution of the hydraulic head is therefore obtained.

To achieve a constant water flow from the outset of the injection, the pumping tube is filled with water before the measuring is started. An electrical valve restrains the water pressure from the pump, which is started before the outset of the injection. The injection is initiated by opening the electrical valve and the measuring period lasts about 6 minutes. Measuring is started 1 minute before the injection and is sustained for 2 minutes after the injection has been stopped. A stationary level of the hydraulic head at the measuring points is reached within of 3 minutes of the injection.

\section{Data interpretation}

The injection method is used for estimating the horizontal hydraulic conductivity due to the vertical source-receiver arrangement.

In the general case of a homogeneous and isotropic full-space the variation of the hydraulic head, $h$, due to point injection of a uniform water flow, Q, is given by (Dam et al., 1996)

$h(r, t)=\frac{Q}{4 \pi r K} \operatorname{erfc}\left(\sqrt{\frac{S r^{2}}{4 K t}}\right)+h_{0}=\frac{Q}{4 \pi K K} \operatorname{erfc}\left(\sqrt{\frac{u}{t}}\right)+h_{0}$

where $S$ is the specific storage, $T$ is the spacing between the injection point and measuring point, $K$ is the hydraulic conductivity, and $h_{0}$ is the initial head. The transient flow given by eq. (1) can be used to determine the specific storage and the hydraulic conductivity. As time passes, $h$ approaches a stationary level given by

$h(r, \infty)=\frac{Q}{4 \pi r K}+h_{0}$

For an inhomogeneous full-space, $\mathrm{K}$ is defined the apparent hydraulic conductivity. The electrical potential due to a point source is given by the same equations as the stationary hydraulic potential. Accordingly, the stationary hydraulic response arising from injection in any layered full-space can be calculated using programs for modelling pole-pole DC-geoelectrical responses.

\section{Relationship between the hydraulic conductivity and the apparent formation factor}

The intrinsic electrical formation factor is given by (Archie, 1942)

$$
F=a \phi^{-m}
$$

where $\phi$ is the effective porosity and $a$ and $m$ are material constants representative of the intrinsic properties of the grain matrix, i.e. grain size, sorting, grain shape, packing etc. For unconsolidated fresh water sands $a$ is about 1 and $m$ is about 1.3 (Urish, 1981). These equations apply for saturated, unconsolidated and clay free formations (Kwader, 1985). If a clay content is present, the formation factor is designated the apparent formation factor and given by (Urish, 1981)

$$
\frac{1}{F_{a}}=\frac{1}{F}+\frac{R_{w}}{R_{m}}
$$

or

$$
F_{a}=\frac{R_{o}}{R_{w}}
$$

where $R_{w}$ is pore fluid resistivity, $\mathbf{R}_{m}$ is the effective resistivity of the matrix in the presence of the pore water and $R_{o}$ is the bulk resistivity. In clay free deposits, $R_{m}$ is much greater than $R_{w}$, so that $F_{a}$ nearly equals $F$. 
Heigold et al. (1979) derive an expression for the relationship between the intrinsic formation factor, $\mathrm{F}$, and the hydraulic conductivity

$K=a_{2} F^{b_{2}}$

where $a_{2}$ and $b_{2}$ are constants. Eq. (6) suggests that for a clay-free formation, $F$ and $\mathrm{K}$ are directly correlated and $\mathrm{F}$ versus $\mathrm{K}$ should plot as a straight line in a bilogaritmic plot.

\section{Field tests}

Field tests were conducted in three borings located approximately $1 \mathrm{~m}$ apart. In each boring three repeated measurements were carried out at intervals of $1 \mathrm{~m}$ in a depth range of $10 \mathrm{~m}$. The method was tested with respect to the subsequent properties:

1. repeatability of consecutive measurements performed at the same level of the formation

2. reproducibility of results obtained at the same level in adjacent bore holes

3. linearity of measurements as a function of flow magnitude

All tests showed high repeatability, reproducibility and linearity and calculated hydraulic conductivities were in agreement with expectations based on pumping tests.

A detailed electrical and gamma log including determinations of the electrical conductivity of the pore fluid were acquired using the ellog drilling method (Sørensen, 1994). The measurements of the pore fluid conductivity were conducted below the ground water table at depth intervals of $0.5 \mathrm{~m}$. Data were used to examine the relationship between the hydraulic conductivity and the apparent formation factor.

\section{Relationship between apparent formation factor and hydraulic conductivity}

The apparent formation factor was calculated from the electrical log and the pore fluid conductivities using eq. (5).
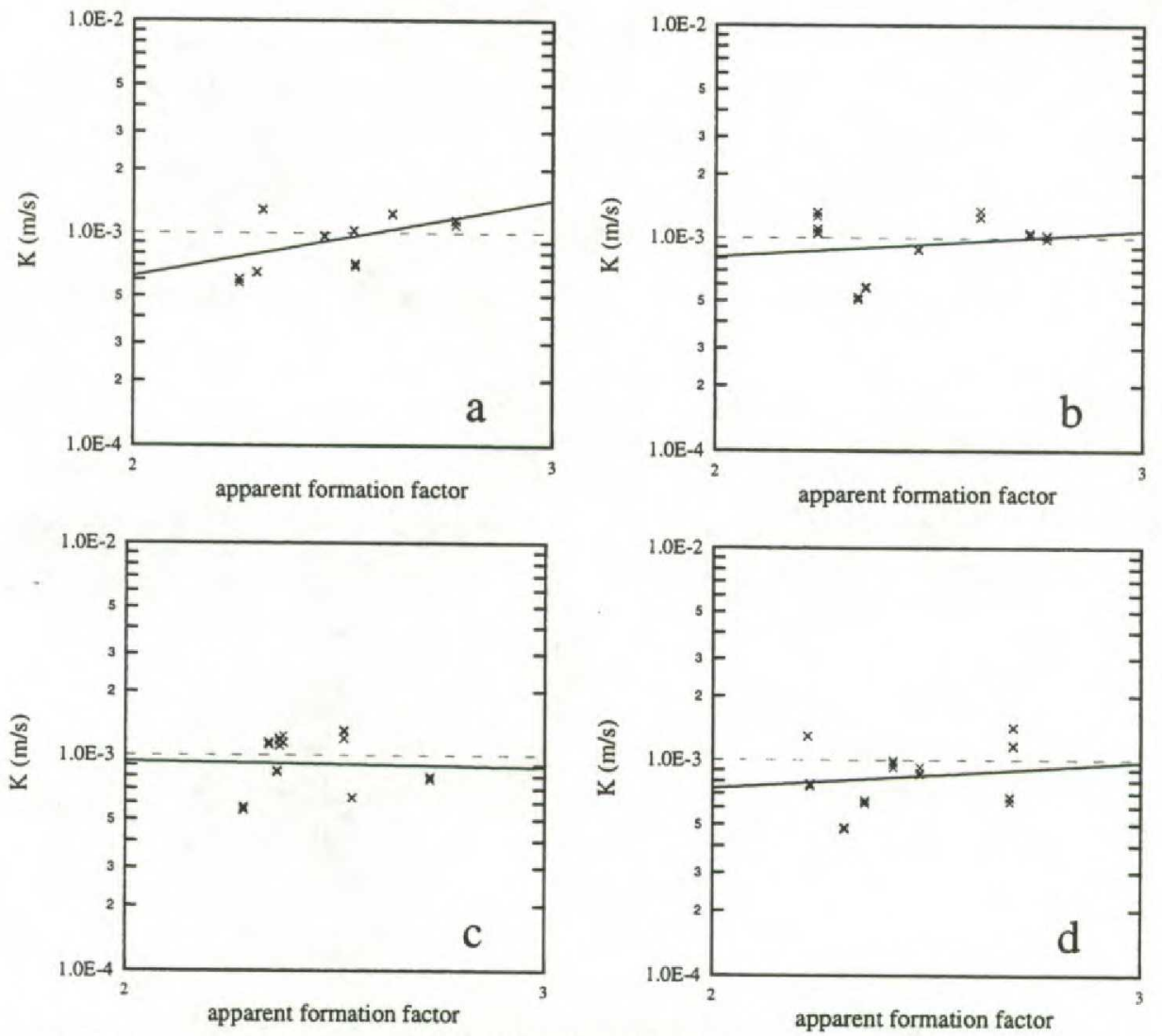

Figure 2: Crossplots between the apparent formation factor and the hydraulic conductivity. Panels a-d represent transducer locations of $0.46,0.88,1.24$ and $1.78 \mathrm{~m}$ above the centre of the injector slots. The straight lines represent least squares fit of the data points. 
Based on the apparent formation factors and the hydraulic conductivities, crossplots between these parameters were made for each of the borings. Crossplots for one of the borings is shown in Figure 2. In order to assess the correlation between the parameters, the data points were fitted by least squares lines in $\log \mathrm{F}_{\mathrm{a}}, \log \mathrm{K}$-space. As can be seen, there is no apparent correlation between the apparent formation factor and the hydraulic conductivities for either of the transducer locations. The residuals between the regression line and the data points are high in each case, which applies to any of the three borings.

Hence, in this study we found no apparent correlation between the apparent formation factor and the hydraulic conductivity.

\section{Conclusions}

A new method for detailed in situ determination of the hydraulic conductivity has been developed. Field tests have been accomplished and a substantial data material including both injection data and ellog data has been collected. The tests have shown that the method fulfils fundamental criteria such as repeatability, reproducibility, consistency and linearity.

Preliminary results indicate that there is no apparent correlation between the apparent formation factor and the hydraulic conductivity in the geologic setting in which the test was accomplished.

Further analysis of the correlation between the electrical and hydraulic data obtained in this work need to be done. In this regard, the apparent hydraulic conductivities should be modelled by a IDinversion program in order to obtain a better estimate of the hydraulic conductivity.

\section{References}

Archie, G.E., 1942, The electrical resistivity $\log$ as an aid in determining some reservoir characteristics. Trans. AIME, 146: 54-62.

Dam, D., Christensen, N.B. and Sørensen, K.I., 1996, Inversion of Transient Head Variation Caused by a Controlled Point Source, in Jacobsen, B.H., Moesgaard, K. and Sibani, P., Ed., Inverse Methods, Interdisciplinary Elements of Methodology, Computation and Application, Springer-Verlag.

Heigold, P.D., Gilkeson, R.H., Cartwright, K. and Reed, P.C., 1979, Aquifer Transmissivity from Surficial Electrical Methods, Ground Water, 17 (4), 338-345.

Kwader, T., 1985, Estimating Aquifer Permeability from Formation Resistivity Factors: Groundwater, 232 (6), 762-766.

Sørensen, K.I., 1994, The Ellog Auger Drilling Method, Proceedings of the Symposium on the Application of Geophysics to Engineering and Environmental Problems, Boston 1994, 985-994.

Urish, D.W., 1981, Electrical Resistivity-Hydraulic Conductivity Relationships in Glacial Outwash Aquifers, Water Resources Research, 17 (2), 95-108. 